\title{
A Novel Identification Method of Thermal Resistances of Thermoelectric Modules Combining Electrical Characterization Under Constant Temperature and Heat Flow Conditions
}

\author{
Saima Siouane, Slaviša Jovanović and Philippe Poure
}

\begin{abstract}
The efficiency of a Thermoelectric Module (TEM) is not only influenced by the material properties, but also by the heat losses due to the internal and contact thermal resistances. In the literature, the material properties are mostly discussed, mainly to increase the well-known thermoelectric figure of merit ZT. Nevertheless, when a TEM is considered, the separate characterization of the materials of the $p$ and $n$ elements is not enough to have a suitable TEM electrical model and evaluate more precisely its efficiency. Only a few recent papers deal with thermal resistances and their influence on the TEM efficiency; mostly, the minimization of these resistances is recommended, without giving a way to determine their values. The aim of the present paper is to identify the internal and contact thermal resistances of a TEM by electrical characterization. Depending on the applications, the TEM can be used either under constant temperature gradient or constant heat flow conditions. The proposed identification approach is based on the theoretical electrical modeling of the TEM, in both conditions. It is simple to implement, because it is based only on open circuit test conditions. A single electrical measurement under both conditions (constant-temperature and constant-heat) is needed. Based on the theoretical electrical models, one can identify the internal and thermal resistances.
\end{abstract}

Index Terms-Thermoelectric Module (TEM); thermal resistances; contact thermal resistance; electrical characterization; identification; electrical model.

\section{INTRODUCTION}

$\mathbf{F}$ OR a small scale power production, a Thermoelectric Module (TEM) appears as the most promising solution. It has the advantages of no moving parts, high reliability, long lifetime being noiseless and environmentally friendly [1], [2]. A thermoelectric module is a solid state semiconductor device that converts heat into electricity by using the Seebeck effect. The TEM is made of $\mathrm{p}$ and $\mathrm{n}$ type semiconductor elements that are electrically connected in series, to generate a higher voltage, and thermally in parallel to keep each semiconductor element at the same thermal gradient. These elements are typically arranged in a planer array and sandwiched between two thermal ceramic plates, where heat is transferred between the hot and the cold sides [3]. Each junction formed by the $\mathrm{p}$ and $\mathrm{n}$ elements is connected to metal contacts (see Fig. 11. When an input heat flow $Q_{H}$ is applied at the hot side,

Saima Siouane, Slaviša Jovanović and Philippe Poure, Institut Jean Lamour (UMR7198) Université de Lorraine, Vandoeuvre lès Nancy, France e-mail: (first_name.name@univ-lorraine.fr). a temperature gradient is created between the hot and cold sides of the TEM, and therefore the appearance of an electrical current $I$ is observed. This phenomenon is known as 'Seebeck effect'.

In Fig 1. $T_{H}^{\prime}$ and $T_{C}^{\prime}$ denote the external hot and cold sides temperatures applied to the TEM respectively, whereas $T_{H}$ and $T_{C}$ denotes the internal hot and cold sides temperatures applied to the $\mathrm{p}$ and $\mathrm{n}$ elements. Notice that the thermal gradient $\Delta T=T_{H}-T_{C}$ applied externally to the TEM is lower than the thermal gradient $\Delta T^{\prime}=T_{H}^{\prime}-T_{C}^{\prime}$ across the $\mathrm{p}-\mathrm{n}$ junction elements. This is due to the contact thermal resistance $\theta_{c}$ between the TEM's semiconductors and their metal contacts. This contact thermal resistance is considered in the TEM electrical modeling presented in this paper.

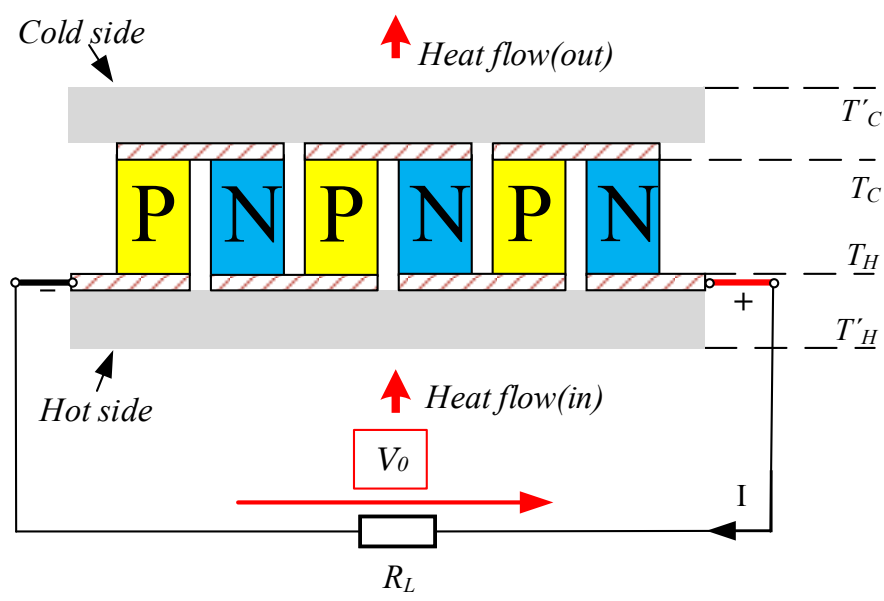

Fig. 1. General Structure of a TEM

Potential applications of thermoelectric modules are in thermal energy harvesting to power wireless sensors or microelectronic devices such as wearable medical sensors [4]. They can also be an energy source to power wristwatches [5]. Moreover, TEMs can also be combined with photovoltaic cells by first converting the solar energy into electricity and heat, and then using the wasted heat to generate electricity [6].

A thermoelectric module is subjected to a limit on its thermoelectric conversion efficiency $(\eta)$, typically around $5 \%$ [7]. As a result, the applications of the thermoelectric module have been limited to specialized domains where the cost 
is a major consideration [8]. The thermoelectric conversion efficiency is defined as the ratio between the energy supplied to the load $P$ and the heat energy $Q_{H}$ absorbed at the hot junction of a TEM:

$$
\eta=\frac{P}{Q_{H}}
$$

The enhancement of the thermoelectric module efficiency is related to the material properties [9]. The key to expanding the range of applications of thermoelectric modules is the development of more efficient materials by improving their internal physical properties [8]. The thermoelectric module efficiency is evaluated by the well-known figure of merit $Z T$ defined as:

$$
Z T=\frac{\alpha^{2} \theta_{m}}{R_{E}} T
$$

where $\alpha$ is the Seebeck coefficient, $\theta_{m}$ the internal thermal resistance, $R_{E}$ the electrical resistance of the TEM, and $T$ the average temperature given by:

$$
T=\frac{T_{H}+T_{C}}{2}
$$

A greater figure of merit $Z T$ indicates more efficient thermoelectric materials [10] having a higher Seebeck coefficient, a lower electrical resistance despite of a higher internal thermal resistance.

Different thermoelectric materials have different values of figure of merit which limit their use to applications with specific temperature range. Fig. 2 [11] shows that for lower temperatures (200 to $400 K)$ bismuth telluride $\left(B i_{2} T e 3\right)$ is preferred while for temperatures between 600 and $800 K$ the material lead telluride $(P b T e)$ is recommended. At higher temperatures (from 800 to $1300 \mathrm{~K}$ ) silicon germanium (SiGe) is used [12], [13]. For all these materials and temperature ranges it holds that $Z T$ is around 1 [14], [15].

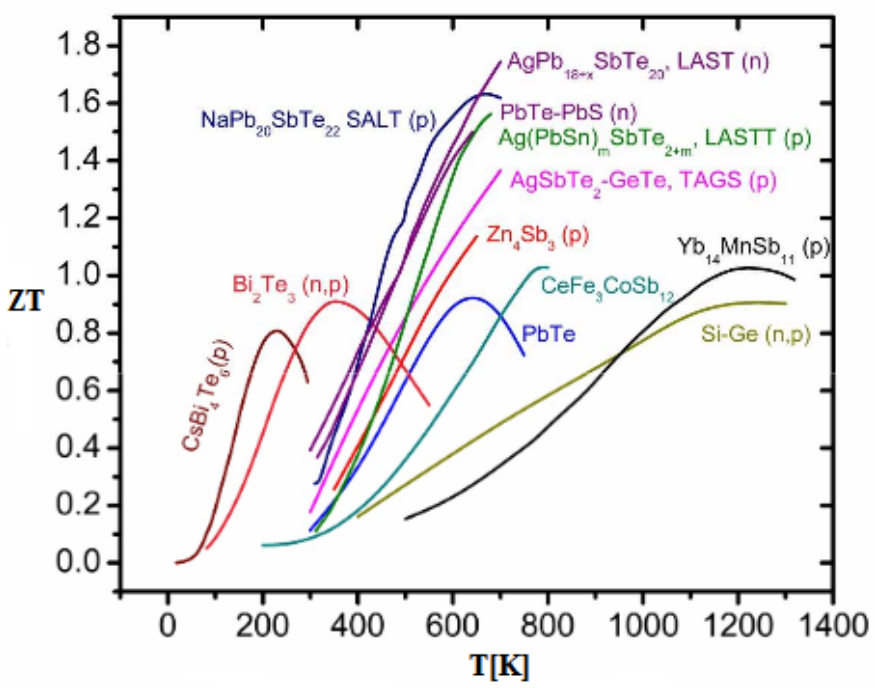

Fig. 2. Figure of merit $Z T$ of different thermoelectric materials performing a function of temperature

Furthermore, the contact thermal resistance $\theta_{c}$, which in bad designs may be of order of magnitude of the internal thermal resistance, can strongly influence the efficiency of a thermoelectric module [16], [17].

The aim of this paper is to identify, in addition to the material properties separately determined for each $p$ and $n$ element, the TEM parameters influencing its efficiency, mainly the internal and contact thermal resistances. Moreover, the knowledge of these parameters is mandatory for electrical modeling and simulation of the TEM. The influence of these parameters on the electrical modeling of the TEM under different operating conditions is detailed in [18].

This paper is built as follows. The electrical modeling of the thermoelectric module is described in Section II. In this section, two conditions are considered: constant temperature gradient and constant heat flow. Section III presents the approach used to identify the thermal resistances of a thermoelectric module using electrical characterization under open circuit conditions for both constant temperature gradient and constant heat flow conditions.

\section{TEM ELECTRICAL MODELING}

The electro-thermal model of a TEM is given in Fig. 3 The electrical part of the model is drawn in black whereas the thermal one is shown in purple. The contact thermal resistance can be modeled by two series resistors $\theta_{c}$ at the top and bottom of the TEM. The internal thermal resistance is called $\theta_{m}$.

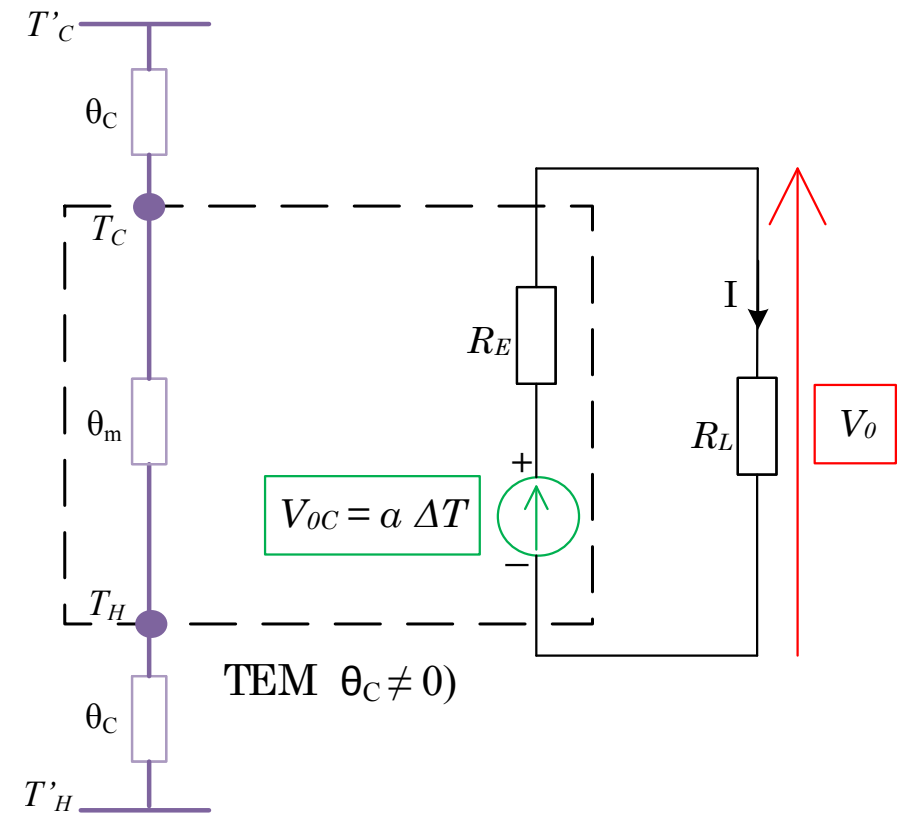

Fig. 3. Electro-thermal model of a TEM

A detailed view of the parameters used in the presented TEM model is shown in Table I.

In this section, the equivalent electrical model of a TEM under constant temperature gradient conditions is first described. Next, considering constant heat flow conditions, the electrical modeling of a TEM is also presented. 
TABLE I

PARAMETERS OF THE TEM

\begin{tabular}{cc}
\hline Parameter & Description \\
\hline$R_{E}$ & TEM electrical resistance \\
\hline$\theta_{m}$ & TEM internal thermal resistance \\
\hline$R_{L}$ & Load resistance \\
\hline$\theta_{c}$ & Seebeck coefficient \\
\hline$\alpha$ & Temperature applied at the hot side of the TEM \\
\hline$T_{H}^{\prime}$ & Temperature applied at the cold side the TEM \\
\hline$T_{C}^{\prime}$ & Hot side temperature at the terminals of p-n elements \\
\hline$T_{H}$ & Cold side temperature at the terminals of p-n elements \\
\hline$T_{C}$ & Input heat flow \\
\hline$Q_{H}$ & Output heat flow \\
\hline$Q_{C}$ &
\end{tabular}

\section{A. TEM modeling under constant temperature gradient con- ditions}

In this case, the external thermal gradient $\Delta T^{\prime}=T_{H}^{\prime}-T_{C}^{\prime}$ across the thermoelecrtic module is maintained constant. Due to the contact thermal resistance $\theta_{c}$, the thermal gradient $\Delta T$ at the terminals of the $\mathrm{p}$ and $\mathrm{n}$ elements is decreased.

The heat flow rates through the hot side of the TEM (the input heat flow $Q_{H}$ ) and its cold side (the output heat flow $Q_{C}$ ), as shown in Fig. 11, are expressed respectively by Fourier's equations [20]-[22]:

$$
\begin{gathered}
Q_{H}=\frac{T_{H}-T_{C}}{\theta_{m}}+\alpha T_{H} I-\frac{1}{2} R_{E} I^{2} \\
Q_{C}=\frac{T_{H}-T_{C}}{\theta_{m}}+\alpha T_{C} I+\frac{1}{2} R_{E} I^{2}
\end{gathered}
$$

By observing the electro-thermal model presented in Fig. 3 and applying the current-voltage analogy to the thermal part of the system where current and voltage correspond to heat flow and temperature respectively, the expression of the heat flow through the metal contacts on the hot and cold sides of the TEM can be formulated as:

$$
\begin{gathered}
Q_{H}=\frac{T_{H}^{\prime}-T_{H}}{\theta_{c}} \\
Q_{C}=\frac{T_{C}-T_{C}^{\prime}}{\theta_{c}}
\end{gathered}
$$

The difference between the heat flows $Q_{H}$ and $Q_{C}$ provides the relationship between the heat flow difference and the power transmitted to the load $R_{L}$ [16]:

$$
Q_{H}-Q_{C}=\frac{T_{H}^{\prime}-T_{H}}{\theta_{c}}-\frac{T_{C}-T_{C}^{\prime}}{\theta_{c}}=V_{O} I
$$

where $V_{O}$ is the output voltage across the load $R_{L}$ under constant temperature gradient conditions, and can be defined by:

$$
\left.V_{O}\right|_{\Delta T^{\prime}=c n s t}=\left.\alpha \Delta T\right|_{\Delta T^{\prime}=c n s t}-R_{E} I
$$

Knowing that $T_{H}=\Delta T+T_{C}$, the temperature applied at the cold side of the $\mathrm{p}$ and $\mathrm{n}$ elements is given by:

$$
T_{C}=-\frac{\theta_{c} V_{O} I+\Delta T-T_{H}^{\prime}-T_{C}^{\prime}}{2}
$$

By replacing the temperature $T_{C}$ by its expression in Eq. 8 the expression of the thermal gradient at the terminals of the $\mathrm{p}$ and $\mathrm{n}$ elements with contact thermal resistances can be expressed by:

$$
\begin{gathered}
\left.\Delta T\right|_{\Delta T^{\prime}=c n s t}=\left(\frac{1}{\alpha \theta_{c} \theta_{m} I+\theta_{m}+2 \theta_{c}}\right) \times \\
\left\{\theta_{c} \theta_{m}\left[\left(\alpha \theta_{c} V_{O}+R_{E}\right) I^{2}+\left(V_{O}-\alpha\left(T_{H}^{\prime}+T_{C}^{\prime}\right)\right) I\right]\right. \\
\left.+\theta_{m} \Delta T^{\prime}\right\}
\end{gathered}
$$

By substituting Eq. 9 in Eq. 11, the thermal gradient at the terminals of the $\mathrm{p}$ and $\mathrm{n}$ elements under constant temperature gradient conditions becomes:

$$
\begin{gathered}
\left.\Delta T\right|_{\substack{\Delta T^{\prime}=c n s t\\
}}=\left(\frac{1}{\alpha^{2} \theta_{c}^{2} \theta_{m} I^{2}-\theta_{m}-2 \theta_{c}}\right) \times \\
\left\{\alpha R_{E} \theta_{c}^{2} \theta_{m} I^{3}+\alpha \theta_{c} \theta_{m}\left(T_{H}^{\prime}+T_{C}^{\prime}\right) I-\theta_{m} \Delta T^{\prime}\right\}
\end{gathered}
$$

By observing Eq. 12 , it can be noticed that the temperature gradient $\Delta T$ seen by the $\mathrm{p}$ and $\mathrm{n}$ elements of the TEM is load current dependent. Thus, to identify it during the TEM functioning, not only the TEM's parameters should be known but also the connected load conditions. To simplify the $\Delta T$ measurement, and consequently the open circuit voltage generated by the TEM, open circuit conditions are usually chosen where the load $R_{L}$ is disconnected from the TEM $(I=0)$, thus bringing Eq. 12 to a much simpler form of temperature divider.

The open circuit voltage generated by the TEM with contact thermal resistances under constant temperature gradient conditions is therefore given by:

$$
\left.V_{O C}\right|_{\Delta T^{\prime}=c n s t}=\left.\alpha \Delta T\right|_{\Delta T^{\prime}=c n s t, I=0}=\frac{\theta_{m}}{\theta_{m}+2 \theta_{c}} \alpha \Delta T^{\prime}
$$

Fig. 4 illustrates the open circuit voltage measurement of the TEM under constant temperature gradient conditions.

\section{B. TEM modeling under constant heat flow conditions}

Under constant heat flow conditions, the input heat flow $Q_{H}$ applied to the hot side and the temperature $T_{C}^{\prime}$ at the cold side of the TEM are maintained constant [23].

The thermal gradient at the terminals of the $\mathrm{p}$ and $\mathrm{n}$ elements for the constant heat flow conditions can be expressed as:

$$
\left.\Delta T\right|_{Q_{H}=c n s t}=\frac{\frac{1}{2} R_{E} \theta_{m} I^{2}-\alpha \theta_{m} T_{C} I+Q_{H} \theta_{m}}{1+\alpha \theta_{m} I}
$$




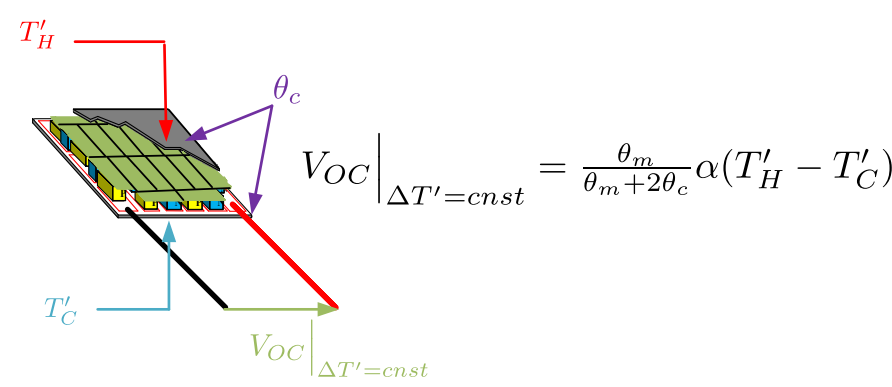

Fig. 4. Open circuit voltage measurement of the TEM under constant temperature gradient conditions

By substituting the expression of $T_{C}$ derived in the previous section and given by Eq. 10 in Eq. 14 , we obtain:

$$
\begin{gathered}
\left.\Delta T\right|_{Q_{H}=c n s t}=\left(\frac{1}{\alpha \theta_{m} I+2}\right) \times \\
\left\{\left(\theta_{m}\left(R_{E}+\alpha \theta_{c} V_{O}\right) I^{2}-\alpha \theta_{m}\left(T_{H}^{\prime}+T_{C}^{\prime}\right) I\right.\right. \\
\left.+2 Q_{H} \theta_{m}\right\}
\end{gathered}
$$

In order to get the expression of the thermal gradient $\Delta T$ only as a function of $Q_{H}$ and $T_{C}^{\prime}, T_{H}^{\prime}$ should be first expressed as a function of these variables. By observing Fig. 3 from the previous section and taking the same current-voltage analogy, the input heat flow $Q_{H}$ can be considered as the current flowing through the thermal resistances $\theta_{m}$ and $\theta_{c}$ connected in series. Thus, by using Eq. 6 the following expression can be obtained for $T_{H}^{\prime}$ :

$$
T_{H}^{\prime}=T_{H}+Q_{H} \theta_{c}=\Delta T+T_{C}+Q_{H} \theta_{c}
$$

Similarly, using Eq. 8, we can write:

$$
Q_{H}-\frac{T_{C}-T_{C}^{\prime}}{\theta_{c}}=V_{O} I
$$

which gives:

$$
T_{C}=-\theta_{c} V_{O} I+T_{C}^{\prime}+Q_{H} \theta_{c}
$$

By substituting Eq. 18 in Eq. 16, and then the obtained result in Eq. 15, the thermal gradient $\Delta T$ at the terminals of the $\mathrm{p}$ and $\mathrm{n}$ elements with contact thermal resistances can be expressed with:

$$
\begin{gathered}
\left.\Delta T\right|_{Q_{H}=c n s t}=\left(\frac{1}{1+\alpha \theta_{m} I}\right) \times \\
\left\{\theta_{m}\left(\frac{1}{2} R_{E}+\alpha \theta_{c} V_{O}\right) I^{2}-\alpha \theta_{m}\left(T_{C}^{\prime}+Q_{H} \theta_{c}\right) I\right. \\
\left.+Q_{H} \theta_{m}\right\}
\end{gathered}
$$

Knowing that the output voltage of the TEM under constant heat flow conditions is given by:

$$
\left.V_{O}\right|_{Q_{H}=c n s t}=\left.\alpha \Delta T\right|_{Q_{H}=c n s t}-R_{E} I
$$

and by replacing Eq 20 in Eq. 19 , the expression of the thermal gradient at the terminals of the $\mathrm{p}$ and $\mathrm{n}$ elements under constant heat flow conditions becomes:

$$
\begin{gathered}
\left.\Delta T\right|_{Q_{H}=c n s t}=\left(\frac{1}{\alpha^{2} \theta_{c} \theta_{m} I^{2}-\alpha \theta_{m} I-1}\right) \times \\
\left(\alpha \theta_{c} \theta_{m} R_{E} I^{3}-\frac{1}{2} \theta_{m} R_{E} I^{2}+\alpha \theta_{m}\left(T_{C}^{\prime}+Q_{H} \theta_{c}\right) I-Q_{H} \theta_{m}\right)
\end{gathered}
$$

As it has been noticed for the constant temperature gradients conditions, the temperature gradient $\Delta T$ of the TEM under constant heat flow conditions is also load current dependent. To eliminate this load current dependence, only the open circuit conditions $(I=0)$ will be considered during the measurements.

Under constant heat flow conditions, the TEM can be also modeled by an equivalent constant voltage source $V_{O C}$ in series with an equivalent internal resistance. Here, the open circuit voltage of the TEM is:

$$
\left.V_{o c}\right|_{Q_{H}=c n s t}=\left.\alpha \Delta T\right|_{Q_{H}=c n s t, I=0}=\alpha \theta_{m} Q_{H}
$$

Fig. 5 illustrates the open circuit voltage measurement of the TEM under constant heat flow conditions.

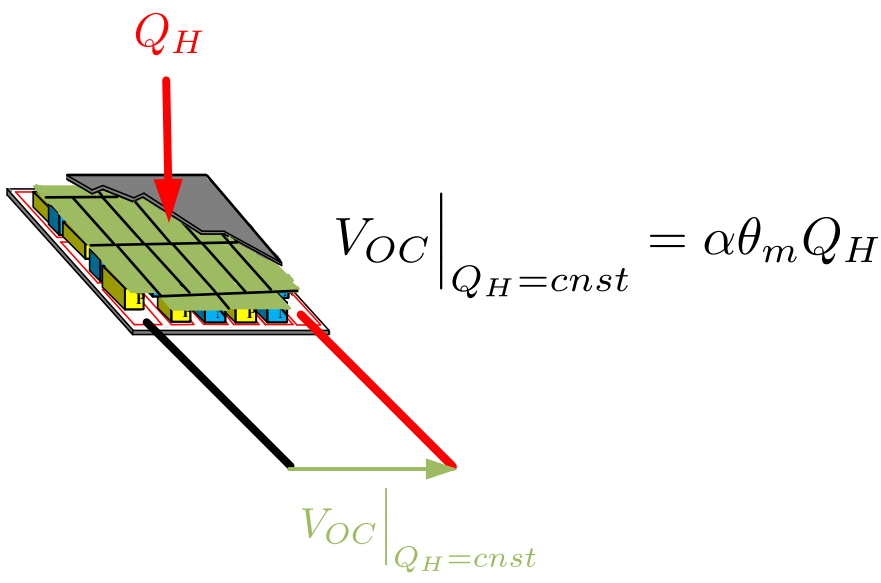

Fig. 5. Open circuit voltage measurement of the TEM under constant heat flow conditions

Based on Eqs. 13 and 22, giving the expressions of the open circuit voltages under both constant temperature gradient and constant heat flow conditions, one can identify the thermal resistances of the TEM only by measuring these two values, as described hereafter in the next section.

\section{IDENTIFICATION OF THERMAL RESISTANCES BY ELECTRICAL CHARACTERIZATION}

The theoretical thermal resistance $\theta_{m}$ of the TEM could be calculated from the following data, if they are provided by the manufacturer:

- $\rho_{m p}$ the thermal resistivity of the $\mathrm{p}$ element.

- $\rho_{m n}$ the thermal resistivity of the $\mathrm{n}$ element.

- $\mathrm{N}$ is the number of pairs of semiconductors of the TEM.

- $A_{p}$ and $A_{n}$ are the cross sectional areas of $\mathrm{p}$ and $\mathrm{n}$ elements, respectively. 
- $L_{p}$ and $L_{n}$ are the length of $\mathrm{p}$ and $\mathrm{n}$ elements, respectively.

The analytical expression of $\theta_{m}$ is given by [24]:

$$
\theta_{m}=\frac{\rho_{m p} L_{p} \rho_{m n} L_{n}}{N\left(\rho_{m p} L_{p} A_{n}+\rho_{m n} L_{n} A_{p}\right)} .
$$

Notice that these data values are not always provided by the manufacturer. Nevertheless, in any case, the thermal resistance $\theta_{m}$ can be identified using electrical characterization. Based on the electrical model of the TEM under constant heat flow conditions, the open circuit voltage measurement allows us to find the value of $\theta_{m}$ by knowing the values of the Seebeck coefficient $\alpha$ and the input heat flow $Q_{H}$, and by using Eq. 22 .

$$
\theta_{m}=\frac{\left.V_{o c}\right|_{Q_{H}=c n s t}}{\alpha Q_{H}} .
$$

The value of $\alpha$ directly depends on the materials used for the TEM manufacturing and is given by:

$$
\alpha=N\left(\alpha_{p}-\alpha_{n}\right) .
$$

where, $\alpha_{p}$ and $\alpha_{n}$ are the Seebeck coefficients of the $\mathrm{p}$ and $\mathrm{n}$ elements, respectively. One can notice that the values of $\alpha_{p}$ and $\alpha_{n}$ are mostly provided by the manufacturer.

In order to identify the contact thermal resistance $\theta_{c}$, the open circuit voltage of the TEM under constant temperature gradient conditions must be measured. This allows us to determine the value of $\theta_{c}$ by substituting the value of $\theta_{m}$ previously determined (Eq. 24), and by knowing the value of the applied thermal gradient $\Delta T^{\prime}$ (test conditions).

$$
\theta_{c}=\frac{\left(\alpha \Delta T^{\prime}-\left.V_{o c}\right|_{\Delta T^{\prime}=c n s t}\right) \theta_{m}}{\left.2 V_{o c}\right|_{\Delta T^{\prime}=c n s t}}
$$

This approach of identifying the internal and contact thermal resistances of a TEM is summarized in Fig. 6 It is based on two open circuit voltage measurements, under both constant temperature gradient and constant heat flow conditions, respectively. The proposed method appears as an efficient and simple way for the TEM's thermal resistances identification.

\section{CONCLUSION}

The Seebeck coefficient $\alpha$ of a TEM is generally provided by the manufacturer; in some cases, the $\theta_{m}$ value can also be calculated from the provided data. However, the value of the contact thermal resistance $\theta_{c}$ is not provided while it is required to electrically model the TEM and evaluate its efficiency. In this paper, the identification of the thermal resistances of a thermoelectric module is presented. To do this, some electrical characterizations are necessary. First, the measurement of the open circuit voltage of the TEM, under constant heat flow conditions, allows calculating the value of the internal thermal resistance $\theta_{m}$. Second, the open circuit voltage of the TEM under constant temperature gradient conditions is measured. This measurement allows to calculate the value of the contact thermal resistance $\theta_{c}$. Notice that

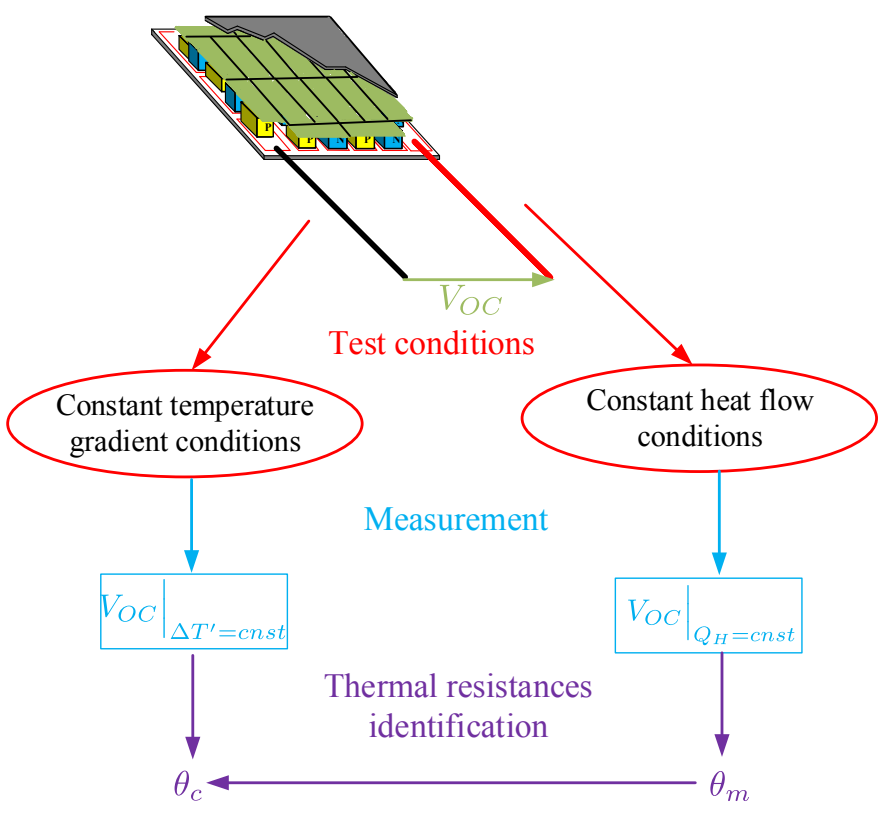

Fig. 6. Identification of internal and contact thermal resistances of the TEM

if the $\theta_{m}$ value is provided by the manufacturer or can be calculated based on the values of $\alpha_{p}$ and $\alpha_{n}$, a single electrical test in open circuit and under constant temperature gradient conditions is needed. Moreover, in addition to the parameter identification, the equations of the electrical model of the TEM are given whatever the operating conditions and by taking into account the internal and contact thermal resistances $\theta_{m}$ and $\left.\theta_{c}\right)$.

\section{REFERENCES}

[1] R. Ahiska and H. Mamur, "Design and implementation of a new portable thermoelectric generator for low geothermal temperatures," Renewable Power Generation, IET, Vol. 7, No. 6, pp. 700-706, 2013.

[2] C-T. Hsu, D-J. Yao, K-J. Ye and B. Yu, "Renewable energy of waste heat recovery system for automobiles," Journal of Renewable and Sustainable Energy, Vol. 2, No. 1, 2010.

[3] A. Dewan, S-U. Ay, M. N-Karim and H. Beyenal, "Alternative power sources for remote sensors: A review," Journal of Power Sources, Elsevier, vol. 245, pp. 129-143, 2014.

[4] J. P. Carmo, L. M. Gonalves and J. H. Correia, “ Thermoelectric microconverter for energy harvesting systems," IEEE Transactions on Industrial Electronics, vol. 57, No.3, pp. 861-867, 2010.

[5] M. Kishi, H. Nemoto, T. Hamao, M. Yamamoto et al, " Micro thermoelectric modules and their application to wristwatches as an energy source," In IEEE International Conference on Thermoelectrics Eighteenth, pp. 301-307, 1999.

[6] D. Kraemer, B.Poudel, H. P. Feng, J. C. Caylor et al , “ Highperformance flat-panel solar thermoelectric generators with high thermal concentration," Nature materials, Vol. 10, no.7, pp. 532-538, 2011.

[7] S. Shanhe and C. Jincan, "Simulation investigation of high efficiency solar thermoelectric generators with inhomogeneously doped nanomaterials," IEEE Trans on indus elec, Vol. 62, No. 6, pp. 3569-3575, 2015.

[8] X-F. Zheng, C-X. Liu, Y-Y. Yan and Q. Wang, "A review of thermoelectrics researchRecent developments and potentials for sustainable and renewable energy applications," Renewable and Sustainable Energy Reviews, Vol.32, pp. 486-503, 2014.

[9] M-H. Elsheikh, D-A. Shnawah, M-F-M. Sabri, S-B-M. Said, M-H. Hassan, et al., "A review on thermoelectric renewable energy: Principle parameters that affect their performance," Renewable and Sustainable Energy Reviews, Vol. 30, pp. 337-355, 2014.

[10] S. Zhou, B-G. Sammakia, B. White and P. Borgesen, "A multiscale modeling of Thermoelectric Generators for conversion efficiency optimization," In Thermal and Thermomechanical Phenomena in Electronic 
Systems (ITherm), 13th IEEE Intersociety Conference on pp. 985-992, 2012.

[11] O. Yamashita, N. Sadatomi, “ Thermoelectric properties of Si1-xGex $\left(\mathrm{x}_{\mathrm{i}}=0.10\right)$ with alloy and dopant segregations," Journal of Applied Physics, Vol. 88, pp. 245-251, 2000.

[12] T. M Tritt, H. Bottner, L. Chen, " Thermoelectrics: direct solar thermal energy conversion,” MRS Bull, Vol. 33, pp. 3668, 2008.

[13] D.M. Rowe, CRC handbook of thermoelectrics. London, NY, USA, CRC Press, 1995.

[14] B. Poudel, Q. Hao, Y. Ma, Y. Lan, A, Minnich, et al , "Highthermoelectric performance of nanostructured bismuth antimony telluride bulk alloys," Science, Vol. 320, pp. 634-638, 2008.

[15] W. G. J. H. M. Van Sark, "Feasibility of photovoltaicthermoelectric hybrid modules," Applied Energy, Vol. 88, No. 8, pp. 2785-2790, 2011.

[16] Saima Siouane, Slavisa Jovanovic and Philippe Poure, "Influence of contact thermal resistances on the Open Circuit Voltage MPPT method for Thermoelectric Generators", IEEE International Energy Conference - EnergyCon, Leuven, Belgium, April 4-8, 2016.

[17] B. Rasmus, "The Universal Influence of Contact Resistance on the Efficiency of a Thermoelectric Generator," Journal of electronic materials, Vol. 44, No. 8, pp. 2869-2876, 2015.

[18] Saima Siouane, Slavisa Jovanovic and Philippe Poure, "Fully electrical modeling of thermoelectric generators with contact thermal resistance under different operating conditions", Journal of electronic materials, pp. 1-11, 2016.

[19] M.-J. Dousti, A. Petraglia, and M. Pedram, "Accurate electrothermal modeling of Thermoelectric Generators," In Proceedings of the DATE, pp. 1603-1606, 2015.

[20] M. Freunek, M. Muller, T. Ungan, W. Walker and L-M. Reindl, "New physical model for thermoelectric generators," Journal of electronic materials, Vol. 38, No. 7, pp. 1214-1220, 2009.

[21] G. Fraisse, J. Ramousse, D. Sgorlon and C. Goupil, "Comparison of different modeling approaches for thermoelectric elements, Energy Conversion and Management,“" Elsevier, vol. 65, pp. 351-356, 2013.

[22] E-J. S.Rosado, S-J. Weinstein and R-J. Stevens, "On the Thomson effect in thermoelectric power devices," International Journal of Thermal Sciences, Elsevier, Vol. 67, pp. 5363, 2013.

[23] A. Montecucco, J. Siviter and A-R. Knox, "Constant heat characterisation and geometrical optimisation of thermoelectric generators," Elsevier, Applied Energy, Vol. 149, pp. 248-258, 2015.

[24] N. Karami and N. Moubayed, "New modeling approach and validation of a Thermoelectric Generators," 23rd IEEE In International symposium on industrial electronics (ISIE), pp. 586-591, 2014.

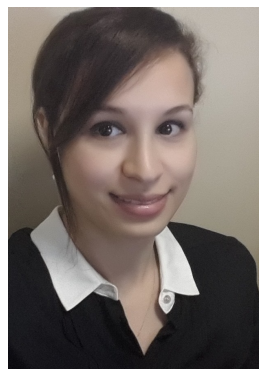

Saima Siouane was born in 1990. She received the Engineer Degree in Electronics from National Polytechnic School, Algiers, Algeria in 2013, the M.S. degree from National School of Engineering of Poitiers, France, in 2014. She is currently pursuing her Ph.D. degree in electronics for energy harvesting system at University of Lorraine - Institute Jean Lamour, Nancy, France.Her research interest mainly focuses on thermoelectric generator, low power DCDC converter and fault tolerant systems.

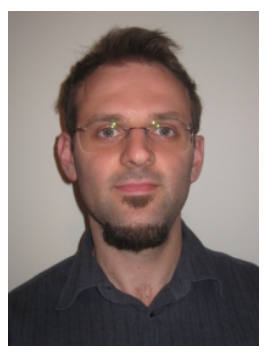

Slaviša Jovanović received the B.S. in electrical engineering from the University of Belgrade, Serbia, in 2004, M.S. and Ph.D degrees in electrical engineering from the University of Lorraine, France, in 2006 and 2009, respectively. From 2009 to 2012, he was with the Diagnosis and Interventional Adaptive Imaging laboratory (IADI), Nancy, France, as a research engineer working on MRIcompatible sensing embedded systems. Then, he joined the Faculty of Sciences and Technologies and the Jean Lamour Institute (UMR 7198), University of Lorraine, Nancy, where he is currently an assistant professor. His main research interests include reconfigurable Network-on-Chips, energy harvesting circuits, neuromorphic architectures and algorithm-architecture matching for real-time signal processing. He is the author and co-author of more than 50 papers in conference proceedings and international peer-reviewed journals, and he holds one patent.

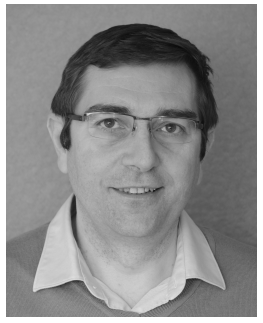

energy havesting.
Philippe Poure was born in 1968. He received the Engineer Degree and Ph.D. Degree in Electrical Engineering from INPL-ENSEM-GREEN, France, in 1991 and 1995 respectively. From 1995 to 2004, he was an Associate Professor and worked at the University Louis Pasteur of Strasbourg, France, in the field of mixed-signal System-On-Chip for control and measurement in Electrical Engineering. Since September 2004, he joined the Universit de Lorraine, Nancy - France and works on fault tolerant power systems, FPGA based real time applications and 